Territórios religiosos...

\title{
TERRITÓRIOS RELIGIOSOS: ESTRATÉGIAS ESPACIAIS DAS IGREJAS CATÓLICA, DEUS É AMOR E UNIVERSAL DO REINO DE DEUS EM BELO HORIZONTE
}

\author{
Ricardo Henrique Palhares ${ }^{1}$ \\ Alexandre Magno Alves Diniz ${ }^{2}$
}

\begin{abstract}
Resumo: A religiosidade, sua organização e apropriação do espaço de Belo Horizonte e as estratégias locacionais por detrás da distribuição espacial dos templos são as inquietações que norteiam esta pesquisa. Ao nos aproximarmos pragmaticamente do objeto escolhido, percebemos no espaço da capital mineira uma tendência da hegemonia católica. Por outro lado, é cada vez maior o número das comunidades evangélicas, configurando uma disputa do território religioso, principalmente da vertente pentecostal, como as Igrejas Deus é Amor e Universal do Reino de Deus. Essas denominações religiosas apresentam lógicas espaciais diferentes no contexto da metrópole, adotando estratégias locacionais distintas na distribuição espacial dos templos, evidenciando uma forte disputa pelo controle do território.
\end{abstract}

Palavras-chave: Pentecostalismo; Catolicismo; Estratégia Locacional, Templos.

\section{RELIGIOUS TERRITORIES: SPATIAL STRATEGIES OF CATHOLIC, DEUS É AMOR E UNIVERSAL DO REINO DE DEUS IN BELO HORIZONTE}

\begin{abstract}
The religiosity, its organization and appropriation of the space of Belo Horizonte; and the locational strategies behind the spatial distribution of temples are concerns that guide this research. As we approach pragmatically the subject of research, we perceive in Belo Horizonte a tendency towards the catholic hegemony. On the other hand, more and more the number of evangelical communities is augmenting, configuring a dispute over the religious territory, mainly by its Pentecostal front, Deus é Amor and Universal do Reino de Deus churches. These religious denominations present different spatial logics in the context of the metropolis, adopting strategic locations in the spatial distribution of temples, evidencing a strong dispute over the control of the territory
\end{abstract}

Keywords: Pentecostalism, Catholicism, Locational Strategy, Temples.

${ }^{1}$ PUC Minas. palharesgeo@yahoo.com.br

${ }^{2}$ PUC Minas. alexandremadiniz@gmail.com

Estudos Geográficos, Rio Claro, 16(1): 41-59, jan./jun. 2018 (ISSN 1678 - 698X) 
Territórios religiosos...

\section{INTRODUÇÃO}

Segundo o Censo Demográfico de 2010, cerca de $60 \%$ da população de Belo Horizonte se afirmam católicos, seguidos dos evangélicos e por aqueles que se declaram sem religião, com $25 \%$ e $8 \%$ respectivamente. As demais religiões, tomadas em conjunto contemplam cerca de $7 \%$ da população. É importante destacar que do total de evangélicos, cerca de $11 \%$ são de origem pentecostal (IBGE, 2010).

A alteração no contexto religioso tem início nas próprias transformações da sociedade, decorrentes das mudanças socioeconômicas determinadas pelo modelo econômico capitalista, que produz um novo e diversificado cenário espacial e religioso em Belo Horizonte, desafiando a nossa compreensão e demandando escrutínio especial. Sobretudo quando se leva em consideração o fato de que o fenômeno religioso constitui-se em importante agente modelador do espaço geográfico (ROSENDAHL, 2005, p.5), e a literatura produzida pela Geografia é embrionária no estudo das estratégias territoriais subjacentes à implantação de templos religiosos.

Diante disso, volta-se a atenção para os espaços sagrados dos principais grupos religiosos da cidade de Belo Horizonte, neste caso, as paróquias e os templos evangélicos de modo a evidenciar as múltiplas formas como o espaço urbano vem sendo explorado por essas religiões. Diante da impossibilidade de lidar com todas as denominações religiosas evangélicas, um recorte se faz necessário, adotando-se como referência duas igrejas de destaque no movimento neoprotestante ${ }^{3}$ : a Igreja Deus é Amor (IPDA) e a Igreja Universal do Reino de Deus (IURD).

Estas igrejas apresentam lideranças fortes, influentes e centralizadoras, além de possuírem um controle doutrinário e administrativo financeiro bastante acentuado. Segundo dados oficiais da IPDA, existem 108 templos em Belo Horizonte, divididos em sede principal, sucursais e templos menores, reunindo mais de 17 mil fiéis. A IPDA orgulha-se de ocupar as favelas e as regiões mais periféricas das cidades, congregando as camadas mais pobres da população (IGREJA PENTECOSTAL DEUS É AMOR, 2016).

Com um discurso imediatista, em menos de uma década desde a sua fundação a IURD espalhou-se pela maioria das capitais do país, utilizando toda sorte de edificações para abrigar os seus cultos (cinemas desativados, galpões, antigas unidades fabris, etc.). Com um discurso de forte apelo popular e cultos performáticos, marcados pela diversidade de estímulos sensoriais que se adaptam a todas as camadas da sociedade, o seu crescimento se deu a passos largos. Atualmente, a capital mineira concentra 68 templos, reunindo mais de 27 mil fiéis (IGREJA UNIVERSAL DO REINO DE DEUS, 2016).

Para os que professam a fé católica, a Arquidiocese de Belo Horizonte está presente em 28 municípios, reunindo 150 paróquias na capital, com mais de 1,4 milhões de fiéis. Além da Catedral Cristo Rei, na Região Norte, estão sendo construídos

\footnotetext{
${ }^{3}$ A tipologia "neoprotestante" reúne o grupo de religiosos que surgiram no período subsequente ao do Protestantismo Clássico no Brasil, na virada do séc. XIX para o séc. XX. Este grupo reúne as principais Igrejas do Protestantismo Pentecostal e Neopentecostal, Carismáticos ou gospel, além do Protestantismo de Renovação denominacional (SCHULTZ, 2005).
}

Estudos Geográficos, Rio Claro, 16(1): 41-59, jan./jun. 2018 (ISSN 1678-698X)

http://www.periodicos.rc.biblioteca.unesp.br/index.php/estgeo 
Territórios religiosos...

mais doze templos em pontos diferentes da cidade (ARQUIDIOCESE DE BELO HORIZONTE, 2016).

Assiste-se a uma expansão sem precedentes do número de igrejas em Minas Gerais. Entre 2010 e 2017, nada menos do que 6.495 organizações religiosas foram abertas em Minas Gerais, o que gera um acréscimo diário de 2,5 igrejas ao longo deste período. Ressalte-se que nesses números figuram além de novas denominações a abertura de filiais de instituições já existentes (FARIA, 2017).

Diante desta crescente concorrência as denominações religiosas devem apresentar lógicas espaciais diferentes no contexto da metrópole, adotando estratégias locacionais distintas na distribuição espacial dos seus templos, evidenciando uma forte disputa pelo controle do território urbano e do estoque de fiéis.

O presente estudo explora a distribuição espacial dos templos das Igrejas Católica, Deus é Amor e Universal do Reino de Deus, relacionando a sua localização com o contexto socioeconômico e a infraestrutura urbana disponível no entorno imediato dos templos presentes em Belo Horizonte. Entender como essas igrejas se apropriam e se organizam no espaço da cidade, descortinando as especificidades de sua racionalidade locacional, favorece o aprofundamento das reflexões acerca das práticas religiosas e de sua influência na construção do espaço urbano de Belo Horizonte.

\section{MATERIAIS E MÉTODOS}

Os Censos Demográficos, por pesquisarem todos os domicílios do país, constituem a melhor referência para o estudo das características da população nos municípios brasileiros, fornecendo informações em diferentes níveis de agregação espacial, permitindo, inclusive, análises intraurbanas (IBGE, 2010).

Este estudo utilizou-se do arquivo Base de Informações do Censo Demográfico 2010, intitulado Resultado do Universo por Setor Censitário. Este arquivo é composto por planilhas específicas para cada Unidade da Federação, abrangendo mais de 3.200 variáveis.

O recorte territorial utilizado correspondeu ao município de Belo Horizonte, tendo como unidade de análise os setores censitários, ou seja, a menor unidade territorial formada por uma área contínua, integralmente contida em área urbana ou rural. Os setores censitários asseguram plena cobertura do território estudado e uma análise mais completa das variáveis analisadas (IBGE, 2010).

Para entender as estratégias locacionais das igrejas, foram definidas variáveis socioeconômicas de pessoas e unidades domiciliares, além de variáveis de infraestrutura dos domicílios e do entorno imediato dos templos. Além dos setores censitários, foram adicionados ao recorte territorial os limites de bairros e das regionais de Belo Horizonte para melhor agrupamento e análise da distribuição dos templos religiosos no município.

O banco de dados da pesquisa consistiu em uma planilha contendo os 3.936 setores censitários de Belo Horizonte e o conjunto de variáveis disponíveis nas bases do Censo Demográfico. Através de buscas nos sites oficiais das igrejas, informações

Estudos Geográficos, Rio Claro, 16(1): 41-59, jan./jun. 2018 (ISSN 1678-698X)

http://www.periodicos.rc.biblioteca.unesp.br/index.php/estgeo 
Territórios religiosos...

sobre o número e a localização de templos católicos, IPDA e IURD foram levantadas e, posteriormente, georreferenciadas. Estes pontos foram interpolados sobre os polígonos da malha de setores censitários, permitindo reconhecer o contexto socioeconômico e a infraestrutura urbana disponível no entorno desses espaços sagrados. Nesta etapa foi utilizado o software de geoprocessamento ArcGis 10.3.

Visando identificar as especificidades dos contextos geográficos onde os templos católicos, IPDA e IURD estão localizados trabalhou-se com Análises de Variância (ANOVA), que permitiram comparar a situação socioeconômica e a infraestrutura urbana no entorno imediato dos templos, a partir da utilização de21 variáveis descritas no quadro 1. A Análise de Variância é a técnica estatística que permite verificar a existência de significância estatística entre as médias de grupos de indivíduos em um dado conjunto de variáveis. Ver BLALOCK (1979) para uma discussão detalhada da técnica. Nesta análise foi empregado o software estatístico SPSS 18.

Quadro1: Variáveis empregadas na Análise de Variância

\begin{tabular}{|c|c|}
\hline ARQUIVO PESSOAS - DESCRIÇÃO DAS VARIÁVEIS & ARQUIVO DOMICÍLIO - DESCRIÇÃO DAS VARIÁVEIS \\
\hline Pessoas residentes e cor ou raça - branca & Domicílios particulares permanentes próprios e quitados \\
\hline Pessoas residentes e cor ou raça - preta & Domicílios particulares permanentes alugados \\
\hline Pessoas residentes e cor ou raça - amarela & Domicílios particulares permanentes com mulher responsável e mais 1 morador \\
\hline Pessoas residentes e cor ou raça - parda & $\begin{array}{l}\text { Domicílios particulares com rendimento nominal mensal domiciliar per capita de } \\
\text { mais de } 1 / 4 \text { a } 1 / 2 \text { salário mínimo }\end{array}$ \\
\hline Pessoas responsáveis alfabetizados & $\begin{array}{l}\text { Domicílios particulares com rendimento nominal mensal domiciliar per capta de } \\
\text { mais de } 1 / 2 \text { a } 1 \text { salário mínimo }\end{array}$ \\
\hline Pessoas alfabetizadas com 5 ou mais anos de idade & $\begin{array}{l}\text { Domicílios particulares com rendimento nominal mensal domiciliar per capta de } \\
\text { mais de } 1 \text { a } 2 \text { salários mínimos }\end{array}$ \\
\hline Média do número de moradores em domicílios particulares permanentes & $\begin{array}{l}\text { Domicílios particulares com rendimento nominal mensal domiciliar per capta de } \\
\text { mais de } 2 \text { a } 3 \text { salários mínimos }\end{array}$ \\
\hline \multirow[t]{6}{*}{ Moradores em domicílios particulares permanentes } & $\begin{array}{l}\text { Domicílios particulares permanentes com lixo coletado, banheiro de uso } \\
\text { exclusivo dos moradores ou sanitário e esgotamento sanitário via rede geral de } \\
\text { esgoto ou pluvial }\end{array}$ \\
\hline & Domicílios particulares permanentes com energia elétrica \\
\hline & Domicílio particular permanente próprio com iluminação pública \\
\hline & Domicílio particular permanente próprio com pavimentação \\
\hline & Domicílio particular permanente próprio com calçada \\
\hline & Domicílio particular permanente próprio com meio fio \\
\hline
\end{tabular}

Fonte: Base de informações do Censo Demográfico 2010: Resultado do Universo por setor censitário.

Uma vez realizados os respectivos testes estatísticos com base nas variáveis supracitadas, foram encontradas importantes correspondências entre o contexto socioeconômico e a infraestrutura dos domicílios, de um lado, e a localização espacial dos templos religiosos, que serão discutidos mais adiante neste trabalho. 
Territórios religiosos...

\section{O PANORAMA RELIGIOSO BRASILEIRO}

A capital mineira é reconhecidamente de tradição católica, porém estudos e pesquisas de opinião revelam que não mais do que $30 \%$ dos católicos atendem com alguma regularidade aos serviços da igreja, especialmente aos domingos (ANTONIAZZI, 1997). Provavelmente, a resposta para esta aparente contradição está na distinção entre praticantes assíduos, cuja participação é constante e cujo vínculo de pertença à Igreja católica é forte (15\%); os praticantes ocasionais, cuja participação é menos frequente (15\%); e aqueles cujos vínculos eclesiais são fracos $(70 \%)$ (ANTONIAZZI, 1997, p.75).

O ponto de vista é pertinente, a partir do momento que a cultura atual criou uma situação de pluralismo religioso, que necessariamente torna mais competitiva a coexistência de várias religiões em Belo Horizonte. Sobre esta questão Luckmann (1969, p.134) complementa:

No contexto da sociedade pluralista e complexa do nosso tempo, a cultura não é mais uma estrutura obrigatória de esquemas de interpretação e avaliação (da realidade), ordenados segundo uma bem definida hierarquia de significação, mas é antes um rico, heterogêneo sortimento de possibilidades acessíveis em princípio, a cada indivíduo consumidor.

Ainda segundo Luckmann, esta tendência é denomina de "religião invisível", uma religião que é moldada pelo reconhecimento interior e pessoal do indivíduo, que pode utilizar-se de elementos da tradição de grandes instituições religiosas, mas que não se liga explícita e exteriormente a nenhuma instituição em particular.

Assim, o indivíduo de hoje é estimulado a construir sua identidade, não a partir de um modelo tradicional, mas com base em livres escolhas. "A situação é muito diferente daquela em que o catolicismo detinha uma espécie de monopólio do campo religioso (época do Brasil colônia), ou uma hegemonia muito nítida" (ANTONIAZZI, 1997, p.81).

A nova condição exige do catolicismo uma roupagem alternativa, visto que sua hegemonia, como percebemos, pode criar certa acomodação, perda de influência e prestígio na sociedade contemporânea. Antoniazzi (1997, p.82) cita que "líderes da renovação católica no início do século XX lamentavam a situação herdada do Império e da Colônia: um catolicismo festivo, nada empenhado socialmente, com pouco peso na sociedade civil e fortemente marcado pela ignorância religiosa".

O Arcebispo metropolitano de Belo Horizonte, Dom Walmor Oliveira de Azevedo levantou uma questão sobre a dificuldade de atuação do Catolicismo (WERNECK e KIEFER, 2015).

Estudos Geográficos, Rio Claro, 16(1): 41-59, jan./jun. 2018 (ISSN 1678 — 698X)

http://www.periodicos.rc.biblioteca.unesp.br/index.php/estgeo 
Territórios religiosos...

Será que somos verdadeiramente atentos às necessidades dos fiéis? Estamos presentes na vida das pessoas, sobretudo nos momentos mais difíceis, em situações de sofrimento e luta? Por isso mesmo é importante lembrarmos que não queremos simplesmente consolidar um "número" para dizer que formamos a maioria. O importante é o anúncio do Evangelho, trabalhar para que cada pessoa tenha a oportunidade de viver um verdadeiro encontro com Jesus Cristo.

Parece uma contradição, mas talvez a maior dificuldade do Catolicismo hoje seja a sua comunicação com os fiéis. Em relação às comunicações internas, a lgreja em Belo Horizonte conta com uma grande variedade de organizações, movimentos e pastorais que compõem a Arquidiocese. Grande parte da comunicação entre o Arcebispo e os fiéis é feita por rádio e programas de televisão, principalmente a Rádio América, dirigida particularmente aos mais devotos e um público feminino bastante ativo nas atividades pastorais; e a transmissão de missas dominicais em diferentes emissoras. A mensagem é transmitida também por centenas de boletins paroquiais e o semanário digital Jornal de Opinião, muito apreciado, mas pouco conhecido.

Independente de algumas falhas, as mensagens internas dirigidas aos fiéis praticantes aparentam funcionar de modo satisfatório. "Há sinais concretos de uma maior expansão nesse campo (projeto de um canal de TV próprio; aquisição de uma segunda rádio; melhor articulação dos meios existentes; formação de equipes de comunicação em nível paroquial)" (ANTONIAZZI, 1997, p.80).

Percebemos que a grande dificuldade da Igreja católica refere-se a sua comunicação "externa", voltada para o grande público, seja no processo de informar acerca de atividades eclesiais, seja na prestação de serviços de informação, educação e reflexão crítica.

É evidente que além das dificuldades de comunicação externa da Igreja católica, outro grande problema que vem influindo no trânsito religioso de seus fiéis para outras religiões, ou mesmo a perda da fé, seria a falta de uma redistribuição das responsabilidades no interior da Igreja-Instituição.

Os católicos mais inclinados às práticas do Catolicismo tendem a aceitar sem grandes dificuldades o pluralismo, além da renovação da Igreja no sentido de uma maior diversidade e de uma maior autonomia. No entanto, a classe clerical, regida pela situação estrutural que lhe é peculiar, tem mais dificuldades para mudanças frente à evolução das exigências que a Instituição católica parece ordenar. Os padres estão sobrecarregados de trabalhos, na sua maioria burocrática, por uma excessiva centralização das funções eclesiais no clero e o grande número de fiéis que necessitam de atendimento espiritual (ANTONIAZZI, 1997).

Ao contrário das igrejas católicas, as denominações evangélicas, principalmente as igrejas neoprotestantes, apresentam um dinamismo e fluidez no território muito maior quando se trata da instalação de seus templos e atendimento de seus fiéis. São formadas por uma multiplicidade de grupos, ou templos menores, com certa autonomia e independentes entre si, o que favorece o atendimento dos desejos individuais de experiências religiosas comunitárias ou emocionais.

Estudos Geográficos, Rio Claro, 16(1): 41-59, jan./jun. 2018 (ISSN 1678 — 698X) 
Territórios religiosos...

O presidente do Conselho de Pastores de Minas Gerais - CPMG, pastor Jorge Linhares, da Igreja Batista Templo Getsêmani, em Belo Horizonte, argumenta:

\begin{abstract}
(...) o ser humano antes de tudo busca Deus, o mineiro vai à busca do que a Bíblia ensina e opta pelo que está certo. O católico tem mais tradição do que propriamente prática religiosa, enquanto o evangélico é participativo, sendo os pastores mais próximos do seu rebanho, presentes no cotidiano das famílias (WERNECK e KIEFER, 2015).
\end{abstract}

De acordo com o pastor Jorge Linhares, existem em Minas Gerais em torno de 2,4 mil pastores filiados e sete seminários evangélicos. Na capital são 400 templos, com mais de 20 nomenclaturas, distribuídas entre as tradicionais históricas ou Clássicas (Batista, Metodista, Presbiteriana e Luterana), Pentecostais e Neopentencostais.

Outra diferença marcante entre católicos e evangélicos, e que distingue seus adeptos é o fato de que os evangélicos oram em casa ou na rua, mas nada substitui a presença ou frequência regular aos templos, remetendo a uma regra ou mandamento a ser seguido. Ao contrário dos católicos não praticantes, que preferem o culto aos santos em suas casas.

Em relação aos templos da IPDA e da IURD, percebe-se que as mesmas apresentam diferenças e características em comum no que tange à liturgia e à prática ritualística. Uma característica que é partilhada por ambas as igrejas é a ênfase especial na experiência direta e pessoal com Deus, crença no demônio e certa rejeição às outras religiões. Além disso, existem identidades sociais criadas dentro dessas igrejas, principalmente na instrução fundamentalista que seus pastores recebem.

Ao analisar o trabalho evangélico, embora todo culto seja, em potencial, evangelizador, a IURD tem um trabalho bem menor se comparada a IPDA, e demais igrejas. Segundo as lideranças da Universal, o fiel não precisa compreender a mensagem em si (culto), mas sim, sentir o "mover do Espírito", levando o culto a uma performance mais avivada e espiritualista, valorizando a dimensão sentimental, gerando uma atmosfera mística em torno da prática cúltica.

Sobre a atmosfera de avivamento criada pela IURD, Campos Jr. (1995, p.56) esclarece que a IURD encontrou uma maneira eficaz para sua expansão, referindo-se a própria preparação de seus pastores: "eles recebem uma instrução fundamentalista (como os demais ramos pentecostais), mas se destacam dos demais por introduzirem, nos cultos, um estilo de show".

Assim, a IURD parece ser a mais agressiva na sedução das almas. "A explicação talvez esteja em suas características eclesiais: cultos de massa, centralizados pela liderança pastoral, e ouso intensivo dos meios de comunicação eletrônica" (FERNANDES, 1998, p.49).Em termos de função de poder, Weber e Marx estão de acordo no que se refere ao fato de que a religião cumpre uma função de conservação da ordem social, contribuindo, à sua maneira, para "legitimação" do poder dos "dominantes" e para "domesticação" dos "dominados" (BOURDIEU, 1999. p.32).

É importante salientar que a Igreja, enquanto ser institucional apropriase tanto do lugar quanto dos seus atores sociais. Em um primeiro momento, a Igreja

Estudos Geográficos, Rio Claro, 16(1): 41-59, jan./jun. 2018 (ISSN 1678-698X)

http://www.periodicos.rc.biblioteca.unesp.br/index.php/estgeo 
Territórios religiosos...

enquanto instituição tende a transformar o lugar em território, e em seguida submeter os atores sociais à hierarquia de clero e leigos (GIL FILHO, 2006).

Fazendo uma análise verticalizada sobre a obsenvação de Bourdieu e Gil Filho, percebe-se entre os diferentes grupos religiosos, principalmente por parte da IPDA e IURD, uma contínua propagação de estratégias para a construção deum sistema de fé e práticas religiosas, visando o privilégio exclusivo da gestão dos bens de salvação e das diferentes classes interessadas por seus serviços.

As igrejas católicas, firmes em seus princípios doutrinários e de tradição, se veem na necessidade de dinamizar e qualificar a evangelização para os católicos e não católicos. As Igrejas da Renovação Carismática Cristã (RCC) têm trabalhado muito nesse sentido, principalmente no âmbito local, visando atividades com a comunidade e grupo de jovens.

Seguindo um raciocínio psicológico, as ações da IPDA e IURD, e o oferecimento de seus serviços visam principalmente à conversão religiosa do indivíduo, proporcionando um preenchimento do vazio existencial causador de profunda insatisfação, proporcionando o que faltava. "O convertido, de fato, é o homem ou a mulher em busca de um sistema de crenças que o integrará mais de perto com aquilo por ele considerado como sendo a realidade" (BROWN, 1965, p. 228). Segundo o autor, o homem religioso almeja que a religião possa oferecer novas expectativas a sua vida, resolvendo seus dilemas de forma imediata e oferecendo um refúgio para a solidão que o assola.

É importante lembrar que a religião está relacionada a um conjunto de práticas religiosas e com o sagrado. A religião cristã a qual fazem parte as igrejas aqui analisadas, tanto católicas quanto evangélicas, tem como princípio o seguimento das escrituras bíblicas. Mas apesar da IPDA e da IURD seguirem os preceitos bíblicos, cada denominação segue os princípios fundamentais de sua crença, por meio da qual os fiéis procuram se relacionar com o sagrado.

Com exceção dos católicos, percebe-se não só no contexto belo-horizontino, mas no geral, que os evangélicos se sentem mais fortes quando estão reunidos, por isso procuram estar presentes nos templos buscando sentirem-se protegidos e abrigados, afastando de si os perigos da vida profana, dos vícios e da ruína.

Nesse sentido, a compreensão do espaço como palco das manifestações do sagrado e sua relação com a fé e o poder facilita o entendimento das dinâmicas espaciais dos templos em estudo. Partindo do princípio que o fiel vivencia o sagrado em espaços diferentes do seu habitual, e que os templos são os espaços das experiências, é possível deduzir que o seu ambiente interno proporciona ao homem religioso uma ruptura com o profano (CORRÊA, 2001). Nesta relação, os templos são peças fundamentais para o entendimento da heterogeneidade do espaço.

\section{O CONTEXTO SOCIOECONÔMICO DOS TEMPLOS}

Grande parte das cidades brasileiras apresenta carências socioeconômicas e de infraestrutura e Belo Horizonte não é uma exceção. Buscando criar o contexto para a discussão da organização territorial dos templos religiosos em Belo Horizonte, faz-se

Estudos Geográficos, Rio Claro, 16(1): 41-59, jan./jun. 2018 (ISSN 1678-698X)

http://www.periodicos.rc.biblioteca.unesp.br/index.php/estgeo 
Territórios religiosos...

necessário identificar esses espaços marcados pela precariedade. Segundo dados do IBGE (2010), 13\% da população de Belo Horizonte vivem em aglomerados subnormais ${ }^{4}$, ou seja, em torno de 307 mil pessoas habitam 169 áreas irregulares como favelas, invasões e vilas, totalizando 87,7 mil domicílios. Três desses aglomerados estão entre os 100 maiores do país: Cabana do Pai Tomás (17,2 mil pessoas); Conjunto Taquaril (14,9 mil pessoas); e Alto Vera Cruz (14 mil pessoas). O percentual de moradores que vivem em aglomerados subnormais na capital mineira é superior ao da cidade de São Paulo, em torno de 11,4\%.

O surgimento de boa parte das favelas e aglomerados de Belo Horizonte se deu com a própria criação da cidade, uma vez que muitos operários que chegaram para trabalhar na construção da nova capital acabaram organizando-se de forma precária em terrenos, vilas e aglomerados (RIBEIRO, 2011), dando origem a um mosaico de áreas carentes de infraestrutura urbana, cuja localização pode ser observada na figura 1.

\section{A DISTRIBUIÇÃO ESPACIAL DOS TEMPLOS}

O espaço é continuamente transformado pelas ações humanas, que por sua vez geram nesse mesmo espaço apropriações e territorializações diversas (RAFFESTIN, 1993). As igrejas também são importantes agentes de transformação espacial, alocando templos religiosos, definindo territórios e criando novas possibilidades para o exercício da fé.

Ao analisar a dinâmica espacial dos templos em Belo Horizonte, percebem-se padrões diferenciados (Figura 1). Os templos da IPDA concentram-se, em sua maioria formando núcleos, principalmente em regiões periféricas de grande fluxo de pessoas, próximos a conjuntos habitacionais de baixa renda, e no interior de vilas e favelas/aglomerados. A IPDA soube acompanhar muito bem os processos sociais ocorridos nas décadas de 1980 e 1990, visto que, apesar da maioria dos domicílios serem permanentes, observou-se um ligeiro acréscimo dos domicílios improvisados no período, seja no total de domicílios ou no de favelas, provável consequência da crise habitacional vivenciada no país em 1986 (GUIMARÃES, 2001, p.52).

Ao contrário da IPDA, os templos da IURD não apresentam uma configuração espacial homogênea em Belo Horizonte. Apesar de estarem presentes também em áreas com grande fluxo de pessoas, e nos principais eixos viários, a IURD atua tanto em regiões carentes com pequenos e médios espaços para a evangelização, quanto em regiões de alto desenvolvimento econômico da cidade. Um exemplo é a Catedral da Fé, inaugurada em 2004, na Avenida Olegário Maciel, zona sul de Belo Horizonte. O Templo foi erguido em um terreno de $8,7 \mathrm{mil} \mathrm{m}^{2}$ com custo estimado em $\mathrm{R} \$ 30$ milhões. Atualmente é considerado o maior templo da IURD construído em Minas Gerais, com capacidade para cinco mil pessoas sentadas (IGREJA UNIVERSAL DO REINO DE DEUS, 2016).

${ }^{4} \mathrm{O}$ termo aglomerado subnormal é utilizado para designar áreas como favelas, invasões e comunidades. São classificados os locais que tenham no mínimo 51 domicílios. Além disso, as áreas devem ser fruto de ocupação irregular ou carente de serviços públicos básicos, como água, luz, esgoto e coleta de lixo. A Região Metropolitana de Belo Horizonte concentra $82 \%$ das favelas do Estado (IBGE, 2010).

Estudos Geográficos, Rio Claro, 16(1): 41-59, jan./jun. 2018 (ISSN 1678-698X) 
Territórios religiosos...

Os templos católicos, que são a maioria em Belo Horizonte, apresentam uma configuração espacial mais homogênea no espaço. A figura 1 demonstra uma maior presença nas áreas mais centrais de Belo Horizonte, que compreende as regiões Nordeste, Noroeste, Oeste, Leste e Centro-Sul. Aliás, as regionais Noroeste e CentroSul são aquelas que apresentam o maior número de paróquias (Tabela 1). Os templos católicos estão presentes também em áreas carentes, mas em menor número se comparadas com os templos da IPDA, por exemplo, direcionadas a público alvo diverso.

Figura 1: Localização dos templos no contexto de Belo Horizonte.

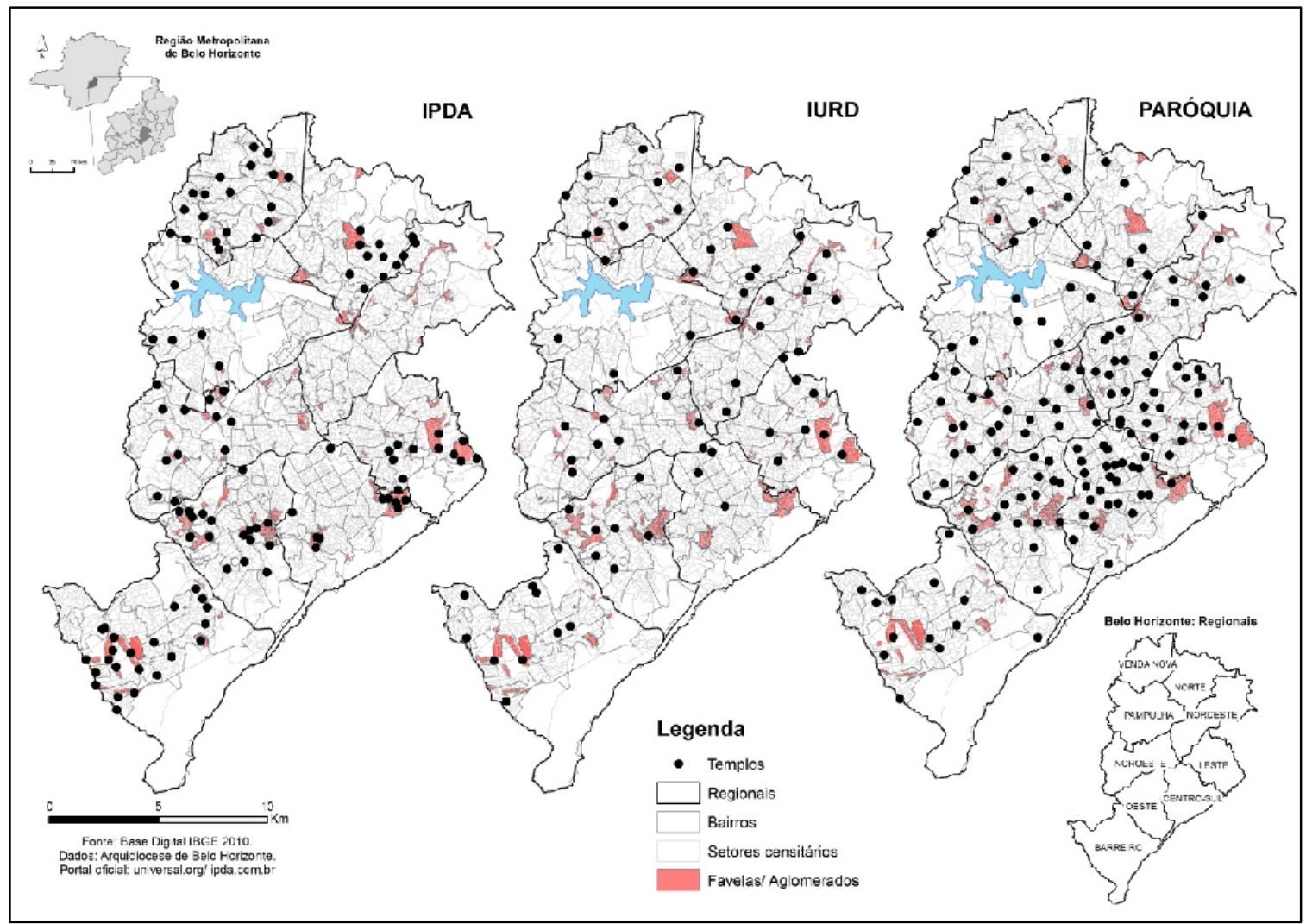

Em relação à distribuição dos templos entre as Regiões Administrativas, observam-se estratégias distintas entre as igrejas na ocupação da cidade. Em áreas com alta densidade demográfica, como é o caso da regional Venda Nova, em números relativos, os templos da IPDA e da IURD são maioria (Tabela 1). Com histórico de ocupação indiscriminada e irregular, a maioria dos bairros da regional Venda Nova surgiu sem o devido planejamento, acarretando problemas de ordem sanitária e de infraestrutura (RIBEIRO, 2011).

Em contrapartida, o crescimento da população para áreas mais periféricas de Belo Horizonte terminou por fomentar, ao longo das décadas, o comércio da região, criando o cenário perfeito para o surgimento e instalação dos templos da IPDA e da IURD. Os templos da IPDA estão presentes nas proximidades e no interior de vilas e

Estudos Geográficos, Rio Claro, 16(1): 41-59, jan./jun. 2018 (ISSN 1678 — 698X) http://www.periodicos.rc.biblioteca.unesp.br/index.php/estgeo 
Territórios religiosos...

favelas, como Minas Caixa, São João Batista, Apolônia, Universo, Copacabana e Santa Mônica; e à margem das principais avenidas da regional Venda Nova. Os templos da IURD, ao contrário, se fazem presentes nos principais eixos viários, com grande fluxo de pessoas e vibrante comércio local, com destaque para a Rua Padre Pedro Pinto e a Avenida Vilarinho.

Tabela 1: Densidade populacional por Regiões Administrativas - Belo Horizonte 2010

\begin{tabular}{|c|c|c|c|c|c|c|c|c|c|}
\hline \multirow{2}{*}{ Região Administrativa } & \multicolumn{6}{|c|}{ № de Templos } & \multirow{2}{*}{ Pessoas residentes } & \multirow{2}{*}{ Área/ km² } & \multirow{2}{*}{ Densidade (Hab./ $\mathrm{Km}^{2}$ ) } \\
\hline & IPDA & $\%$ & IURD & $\%$ & Paróquias & $\%$ & & & \\
\hline BARREIRO & 21 & 19,4 & 10 & 14,7 & 14 & 9,3 & 282.552 & 53,233 & $5.307,80$ \\
\hline CENTRO-SUL & 10 & 9,3 & 4 & 5,9 & 28 & 18,7 & 272.285 & 31,035 & $8.773,40$ \\
\hline LESTE & 12 & 11,1 & 8 & 11,8 & 18 & 12,0 & 249.273 & 28,864 & $8.636,20$ \\
\hline NORDESTE & 3 & 2,8 & 9 & 13,2 & 19 & 12,7 & 291.110 & 39,206 & $7.425,20$ \\
\hline NOROESTE & 11 & 10,2 & 9 & 13,2 & 28 & 18,7 & 331.362 & 36,952 & $8.967,40$ \\
\hline NORTE & 9 & 8,3 & 7 & 10,3 & 8 & 5,3 & 212.953 & 33,343 & $6.386,70$ \\
\hline OESTE & 18 & 16,7 & 7 & 10,3 & 17 & 11,3 & 286.118 & 32,331 & $8.849,60$ \\
\hline PAMPULHA & 7 & 6,5 & 3 & 4,4 & 8 & 5,3 & 187.315 & 38,549 & $4.859,10$ \\
\hline VENDA NOVA & 17 & 15,7 & 11 & 16,2 & 10 & 6,7 & 262.183 & 28,309 & $9.261,40$ \\
\hline TOTAL & 108 & 100 & 68 & 100 & 150 & 100 & 2.375 .151 & 321,823 & $7.380,30$ \\
\hline
\end{tabular}

Fonte: IBGE - Censo 2010

Em relação aos templos católicos, os dados da tabela 1 demonstram forte presença, tanto em termos absolutos quanto relativos, nas regionais Centro-Sul e Noroeste, com 28 paróquias em cada regional, cerca de $37,4 \%$ do total de templos católicos em Belo Horizonte. Com histórico de consolidação antigo (1893 - 1897), a regional Noroeste é a que apresenta o maior número de residentes, tendo a Igreja católica grande importância para o dinamismo da região, com destaque para o surgimento em 1926 do Seminário Coração Eucarístico, hoje, atual campus da PUC Minas no bairro Coração Eucarístico.

A regional Centro-Sul abrigou o sítio e o projeto originais da cidade planejada de Belo Horizonte, inaugurada em 1897. A área urbana, delimitada pela Avenida do Contorno, recebeu ao longo do tempo a infra estrutura urbana necessária, como vias de transporte, saneamento básico e iluminação pública(RIBEIRO, 2011). A regional foi por muito tempo responsável por concentrar a maior parte dos serviços e atividades como comércio, escolas, hospitais, e especialmente templos da Igreja católica. Em 1921, a cidade abrigava apenas três templos católicos, todos localizados na área central de Belo Horizonte: a Igreja de São José; Igreja Nossa Senhora do Rosário; e a Igreja de Nossa Senhora da Boa Viagem (atual Catedral de Belo Horizonte). Não por acaso, atualmente, a maioria dos templos católicos ainda se fazem presentes na regional Centro-Sul.

Dentre as regionais de Belo Horizonte, a que apresentou o maior dinamismo ao longo das décadas foi a do Barreiro. Segundo Ribeiro (2011), o advento das indústrias, e, em seguida, o desenvolvimento do comércio, surgimento de grandes eixos viários e a criação do metrô na região, fizeram com que o Barreiro se tornasse uma das regionais mais estratégicas de Belo Horizonte. A regional concentra o maior número de templos da IPDA, totalizando 21 edificações religiosas $(19,4 \%)$, número que equivale a dez

Estudos Geográficos, Rio Claro, 16(1): 41-59, jan./jun. 2018 (ISSN 1678-698X) 
vezes aquele encontrado de templos da IURD. O número é superior também ao número de paróquias identificadas.

Seguindo a mesma lógica locacional, a maioria dos templos da IPDA está próxima às principais vilas da regional Barreiro, dentre elas: Conjunto Jatobá I("Vila Santa Rita"); Conjunto Jatobá II (“Vila Pinho"); Conjunto Jatobá III (“Vila Castanheira”); Marieta I e II ("Vilinha"); Conjunto Bonsucesso e Vila Cemig. Os templos também estão presentes ao longo de importantes entroncamentos viários como a Avenida Perimetral e a Avenida Waldyr Soeiro Emrich, um dos principais acessos à Estação Diamante, que apresenta enorme movimentação diária de passageiros atendidos pelo metrô e pelas diversas linhas de ônibus da região.

Outras regionais de Belo Horizonte destacam-se em relação ao grande adensamento urbano, com histórico de ocupação antigo e áreas de ocupação irregulares. A regional Leste, por exemplo, apresentou um equilíbrio em termos relativos entre os templos religiosos, com uma pequena predominância em termos absolutos de templos católicos. O inverso pode ser observado na regional Oeste, com predominância dos templos da IPDA, tanto em termos absolutos e relativos.

A IPDA levou em conta as características da região para a instalação de seus templos, visto que a regional Oeste apresentou ao longo das décadas um processo de expansão urbana descontínua, em parte, devido a sua topografia bastante acidentada. Este fato acarretou no surgimento de grandes vilas, como é o caso do aglomerado Morro das Pedras, nome originado da presença de uma antiga pedreira na região (RIBEIRO, 2011). Além disso, boa parte da região ainda é desprovida de saneamento básico, iluminação pública e segurança. É nesse cenário que os templos da IPDA encontram terreno fértil para instalação de seus templos.

As regionais Norte e Pampulha registraram os menores números (menos de 10,3\%) de templos religiosos, sejam católicos, da IPDA e da IURD (Tabela 1). Segundo a Arquidiocese de Belo Horizonte, novos templos estão sendo construídos, principalmente nas áreas mais carentes da cidade. Na regional Norte, por exemplo, será edificada a nova Catedral da cidade. A Catedral Cristo Rei, projeto do arquiteto Oscar Niemeyer, está em construção no vetor Norte, área de expansão urbana da $\mathrm{RMBH}$, no bairro Jaqueline. A nave principal do templo terá 100 metros de altura, com capacidade total para 20 mil fiéis (ARQUIDIOCESE DE BELO HORIZONTE, 2016).

Uma análise pormenorizada da distribuição espacial dos templos religiosos em Belo Horizonte demonstrou distintas lógicas espaciais por parte das denominações em questão. Os dados demonstraram que os templos da IURD assumem uma posição intermediária, quando comparados aos templos da IPDA e católicos. A IURD está presente em contextos sociais distintos, pregando para uma população de diferentes estratos da sociedade. Os templos da IPDA atuam como verdadeiros agentes assistencialistas, encontrando-se mais presentes em áreas carentes e desprovidas de infraestrutura básica. O inverso pode ser observado em relação aos templos católicos, ausentes nas regiões periféricas, atuando em sua maioria, sobretudo nas áreas mais centrais e com melhor desenvolvimento econômico. 
Territórios religiosos...

\section{O CONTEXTO SOCIOESPACIAL DOS TEMPLOS RELIGIOSOS}

Esta seção traz os resultados do perfil das áreas onde estão instalados os templos religiosos, caracterizando o seu contexto socioespacial, a partir da análise de variáveis relacionadas aos moradores do entorno dos templos e suas condições de vida. Os testes estatísticos indicaram diferenças estatisticamente significativas para todas as variáveis aqui analisadas, demonstrando a forte e consistente diferença entre os contextos nos quais templos católicos, IURD e IPDA estão inseridos. Esses resultados confirmam a adoção de estratégias espaciais e a busca por públicos-alvo específicos por parte de cada denominação religiosa.

Em linhas gerais, pode-se dizer que os templos católicos estão inseridos em contextos sociais mais elitizados, em sua maioria nas áreas mais centrais da cidade (Região Centro-Sul), onde os seus moradores gozam de boas condições de vida e recursos materiais. Por sua vez, a IPDA e a IURD têm estratégias diferentes, focando outras realidades.

Em relação ao quesito cor ou raça, os templos católicos encontram-se em áreas marcadas pelo predomínio de pessoas brancas, ao passo que os templos IPDA e IURD estão associados a contextos onde a proporção de pretos, pardos e amarelos é mais forte (Tabela 2).

Tabela 2: Características das Pessoas/População Residente por Cor ou Raça- 2010

\begin{tabular}{|c|c|c|c|c|c|c|c|c|c|}
\hline Variáveis & Templos & № & Média & Desv.Padrão & Erro Padrão & $\begin{array}{c}\text { Soma dos } \\
\text { Quadrados }\end{array}$ & GL & $\mathbf{F}$ & SIG. \\
\hline \multirow{4}{*}{ Pessoas residentes e cor ou raça - branca } & IPDA & 108 & 34,07 & 12,91 & 1,24 & $28.818,64$ & 2 & 50,250 & 0,000 \\
\hline & IURD & 68 & 44,93 & 16,81 & 2,04 & $92.622,00$ & 323 & & \\
\hline & CATOLICA & 150 & 55,44 & 19,36 & 1,58 & $121.440,64$ & 325 & & \\
\hline & Total & 326 & 46,17 & 19,33 & 1,07 & & & & \\
\hline \multirow{4}{*}{ Pessoas residentes e cor ou raça - preta } & IPDA & 108 & 13,70 & 6,58 & 0,63 & $1.921,00$ & 2 & 26,968 & 0,000 \\
\hline & IURD & 68 & 10,73 & 5,87 & 0,71 & $11.503,99$ & 323 & & \\
\hline & CATOLICA & 150 & 8,17 & 5,54 & 0,45 & $13.424,99$ & 325 & & \\
\hline & Total & 326 & 10,54 & 6,43 & 0,36 & & & & \\
\hline \multirow{4}{*}{ Pessoas residentes e cor ou raça - amarela } & IPDA & 108 & 1,36 & 1,63 & 0,16 & 17,08 & 2 & 5,712 & 0,004 \\
\hline & IURD & 68 & 0,94 & 1,03 & 0,12 & 482,97 & 323 & & \\
\hline & CATOLICA & 150 & 0,85 & 0,92 & 0,08 & 500,05 & 325 & & \\
\hline & Total & 326 & 1,04 & 1,24 & 0,07 & & & & \\
\hline \multirow{4}{*}{ Pessoas residentes e cor ou raça - parda } & IPDA & 108 & 50,71 & 10,42 & 1,00 & $14.797,17$ & 2 & 42,330 & 0,000 \\
\hline & IURD & 68 & 43,25 & 12,67 & 1,54 & $56.454,46$ & 323 & & \\
\hline & CATOLICA & 150 & 35,42 & 15,12 & 1,23 & $71.251,62$ & 325 & & \\
\hline & Total & 326 & 42,12 & 14,81 & 0,82 & & & & ' \\
\hline
\end{tabular}

Fonte: Agregado por setores censitários. Censo Demográfico 2010.

Apesar de o IBGE não disponibilizar os microdados na escala dos setores censitários, existem algumas informações agregadas sobre escolaridade, notadamente sobre alfabetização, que passaremos a examinar ${ }^{5}$. O percentual de responsáveis por unidades domiciliares alfabetizados é bastante significativo no conjunto analisado, fazendo-se ainda mais importante no contexto onde os templos católicos estão presentes. Processo semelhante se dá em relação às pessoas com cinco ou mais anos de idade alfabetizadas (Tabela 3).

${ }^{5} \mathrm{O}$ IBGE considera como alfabetizada a pessoa capaz de ler e escrever um bilhete simples no idioma que conhecesse.

Estudos Geográficos, Rio Claro, 16(1): 41-59, jan./jun. 2018 (ISSN 1678-698X)

http://www.periodicos.rc.biblioteca.unesp.br/index.php/estgeo 
Territórios religiosos...

Tabela 3: Características das Pessoas/ Alfabetização - 2010

\begin{tabular}{|c|c|c|c|c|c|c|c|c|c|}
\hline Variáveis & Templos & № & Média & Desv.Padrão & Erro Padrão & $\begin{array}{l}\text { Soma dos } \\
\text { Quadrados }\end{array}$ & GL & $\mathbf{F}$ & SIG. \\
\hline \multirow{3}{*}{ Pessoas responsáveis alfabetizados } & $\begin{array}{l}\text { IPDA } \\
\text { IURD }\end{array}$ & $\begin{array}{c}108 \\
68\end{array}$ & $\begin{array}{l}93,37 \\
96,18\end{array}$ & $\begin{array}{l}5,45 \\
4,20\end{array}$ & $\begin{array}{l}0,52 \\
0,51\end{array}$ & $\begin{array}{l}1.144,47 \\
5.957,66\end{array}$ & $\begin{array}{c}2 \\
323\end{array}$ & 31,024 & 0,000 \\
\hline & CATOLICA & 150 & 97,63 & 3,27 & 0,27 & $7.102,13$ & 325 & & \\
\hline & Total & 326 & 95,92 & 4,67 & 0,26 & & & & \\
\hline \multirow{4}{*}{$\begin{array}{l}\text { Pessoas alfabetizadas com } 5 \text { ou mais anos de } \\
\text { idade }\end{array}$} & IPDA & 108 & 32,22 & 3,49 & 0,34 & 452,00 & 2 & 13,267 & 0,000 \\
\hline & IURD & 68 & 34,14 & 4,92 & 0,60 & $5.502,21$ & 323 & & \\
\hline & CATOLICA & 150 & 34,88 & 4,16 & 0,34 & $5.954,21$ & 325 & & \\
\hline & Total & 326 & 33,84 & 4,28 & 0,24 & & & & \\
\hline
\end{tabular}

Fonte: Agregado por setores censitários. Censo Demográfico 2010.

A tabela 4 traz informações sobre o número médio de moradores em domicílios particulares permanentes, indicando que no conjunto analisado existem em média 3,16 moradores por domicílio. No entanto, cabe ressaltar que os locais onde se encontram os templos católicos o número médio de pessoas é menor $(3,05)$, apresentando-se também abaixo da média os lugares onde os templos IURD estão presentes. Por sua vez, o contexto onde os templos IPDA se instalaram contabilizam uma média de 3,32 pessoas. Além disso, os templos católicos estão em áreas com uma proporção ligeiramente maior de moradores vivendo em domicílios particulares permanentes, quando comparados aos templos das demais denominações religiosas (Tabela 4).

Tabela 4: Características das Pessoas/ Moradores por Domicílio - 2010

\begin{tabular}{|c|c|c|c|c|c|c|c|c|c|}
\hline Variáveis & Templos & № & Média & Desv.Padrão & Erro Padrão & $\begin{array}{l}\text { Soma dos } \\
\text { Quadrados }\end{array}$ & GL & $\mathbf{F}$ & SIG. \\
\hline $\begin{array}{l}\text { Média do número de moradores em domicílios } \\
\text { particulares permanentes }\end{array}$ & $\begin{array}{c}\text { IPDA } \\
\text { IURD } \\
\text { CATOLICA } \\
\text { Total }\end{array}$ & $\begin{array}{c}108 \\
68 \\
150 \\
326\end{array}$ & $\begin{array}{l}3,32 \\
3,13 \\
3,05 \\
3,16 \\
\end{array}$ & $\begin{array}{l}0,32 \\
0,36 \\
0,34 \\
0,36\end{array}$ & $\begin{array}{l}0,03 \\
0,04 \\
0,03 \\
0,02\end{array}$ & $\begin{array}{c}4,86 \\
37,45 \\
42,30\end{array}$ & $\begin{array}{c}2 \\
323 \\
325\end{array}$ & 20,939 & 0,000 \\
\hline $\begin{array}{l}\text { Moradores em domicílios particulares } \\
\text { permanentes }\end{array}$ & $\begin{array}{c}\text { IPDA } \\
\text { IURD } \\
\text { CATOLICA } \\
\text { Total }\end{array}$ & $\begin{array}{c}108 \\
68 \\
150 \\
326\end{array}$ & $\begin{array}{l}30,39 \\
32,50 \\
33,26 \\
32,15\end{array}$ & $\begin{array}{l}3,21 \\
4,94 \\
4,11 \\
4,22\end{array}$ & $\begin{array}{l}0,31 \\
0,60 \\
0,34 \\
0,23\end{array}$ & $\begin{array}{c}528,89 \\
5.257,66 \\
5.786,55\end{array}$ & $\begin{array}{c}2 \\
323 \\
325\end{array}$ & 16,246 & 0,000 \\
\hline
\end{tabular}

Fonte: Agregado por setores censitários. Censo Demográfico 2010.

Em relação à condição de moradia, a tabela 5 traz resultados interessantes. Existe uma equivalência na proporção de indivíduos vivendo em domicílios particulares permanentes próprios e quitados nas cercanias de templos católicos e IPDA, sendo significativamente menor a proporção de pessoas nesta condição nos locais onde os templos IURD se encontram. Fenômeno semelhante se dá em relação aos domicílios particulares permanentes alugados, sendo que os locais onde os templos católicos e IPDA se instalaram apresentam números parecidos, enquanto os templos IURD estão em lugares onde existe uma maior proporção de locatários.

A tabela 5 também traz relevantes resultados relativos aos novos arranjos familiares e à condição feminina. Note-se que a proporção de mulheres chefes de família habitando com mais um morador é bastante expressiva no conjunto analisado, fazendo-se ainda mais expressiva no entorno dos templos da IPDA. 
Territórios religiosos...

Tabela 5: Características do Domicílio/ Tipo e responsável pelo domicílio - 2010

\begin{tabular}{|c|c|c|c|c|c|c|c|c|c|}
\hline Variáveis & Templos & № & Média & Desv.Padrão & Erro Padrão & $\begin{array}{l}\text { Soma dos } \\
\text { Quadrados }\end{array}$ & GL & $\mathbf{F}$ & SIG. \\
\hline \multirow{4}{*}{$\begin{array}{l}\text { Domicílios particulares permanentes próprios e } \\
\text { quitados }\end{array}$} & IPDA & 108 & 72,11 & 14,12 & 1,36 & $1.401,67$ & 2 & 4,165 & 0,016 \\
\hline & IURD & 68 & 66,95 & 13,09 & 1,59 & $54.354,57$ & 323 & & \\
\hline & CATOLICA & 150 & 72,01 & 12,03 & 0,98 & $55.756,24$ & 325 & & \\
\hline & Total & 326 & 70,99 & 13,10 & 0,73 & & & & \\
\hline \multirow{4}{*}{ Domicílios particulares permanentes alugados } & IPDA & 108 & 19,65 & 10,62 & 1,02 & $1.378,62$ & 2 & 6,548 & 0,002 \\
\hline & IURD & 68 & 25,28 & 11,57 & 1,40 & $34.002,42$ & 323 & & \\
\hline & CATOLICA & 150 & 20,99 & 9,33 & 0,76 & $35.381,04$ & 325 & & \\
\hline & Total & 326 & 21,44 & 10,43 & 0,58 & & & & \\
\hline \multirow{4}{*}{$\begin{array}{l}\text { Domicílios particulares permanentes com mulher } \\
\text { responsável e mais } 1 \text { morador }\end{array}$} & IPDA & 108 & 38,04 & 10,96 & 1,05 & & & & \\
\hline & IURD & 68 & 34,25 & 9,27 & 1,12 & 629,39 & 2 & 3 & 0,044 \\
\hline & CATOLICA & 150 & 35,99 & 9,59 & 0,78 & $32.309,66$ & 323 & & \\
\hline & Total & 326 & 36,30 & 10,07 & 0,56 & $32.939,05$ & 325 & & \\
\hline
\end{tabular}

Fonte: Agregado por setores censitários. Censo Demográfico 2010.

Em relação à renda, a análise de variância demonstrou contextos sociais bem definidos. As áreas onde estão os templos da IPDA e, em segundo lugar da IURD, são os que apresentam a maior proporção de domicílios particulares com rendimento nominal mensal domiciliar per capita abaixo de dois salários mínimos. Por sua vez, o contexto dos templos católicos apresenta maior proporção de unidades domiciliares com renda per capita acima de três salários mínimos (Tabela 6).

Tabela 6: Características do Domicílio/ Rendimento nominal per capta - 2010

\begin{tabular}{|c|c|c|c|c|c|c|c|c|c|}
\hline Variáveis & Templos & № & Média & Desv.Padrão & Erro Padrão & $\begin{array}{l}\text { Soma dos } \\
\text { Quadrados }\end{array}$ & GL & $\mathbf{F}$ & SIG. \\
\hline $\begin{array}{l}\text { Domicílios particulares com rendimento } \\
\text { nominal mensal domiciliar per capita de } \\
\text { mais de } 1 / 4 \text { a } 1 / 2 \text { salário mínimo }\end{array}$ & $\begin{array}{c}\text { IPDA } \\
\text { IURD } \\
\text { CATOLICA } \\
\text { Total }\end{array}$ & $\begin{array}{c}108 \\
68 \\
150 \\
326\end{array}$ & $\begin{array}{c}21,06 \\
12,80 \\
8,59 \\
13,60\end{array}$ & \begin{tabular}{c|}
11,38 \\
7,95 \\
7,96 \\
10,72
\end{tabular} & $\begin{array}{l}1,09 \\
0,96 \\
0,65 \\
0,59\end{array}$ & $\begin{array}{l}9.817,50 \\
27.519,21 \\
37.336,71\end{array}$ & $\begin{array}{c}2 \\
323 \\
325\end{array}$ & 57,615 & 0,000 \\
\hline $\begin{array}{l}\text { Domicílios particulares com rendimento } \\
\text { nominal mensal domiciliar per capita de } \\
\text { mais de } 1 / 2 \text { a } 1 \text { salário mínimo }\end{array}$ & $\begin{array}{c}\text { IPDA } \\
\text { IURD } \\
\text { CATOLICA } \\
\text { Total } \\
\end{array}$ & $\begin{array}{c}108 \\
68 \\
150 \\
326\end{array}$ & $\begin{array}{l}35,27 \\
28,16 \\
20,91 \\
27,18\end{array}$ & $\begin{array}{c}8,96 \\
11,48 \\
14,01 \\
13,55\end{array}$ & $\begin{array}{l}0,86 \\
1,39 \\
1,14 \\
0,75\end{array}$ & $\begin{array}{l}13.020,17 \\
46.648,38 \\
59.668,55\end{array}$ & $\begin{array}{c}2 \\
323 \\
325\end{array}$ & 45,077 & 0,000 \\
\hline $\begin{array}{l}\text { Domicílios particulares com rendimento } \\
\text { nominal mensal domiciliar per capita de } \\
\text { mais de } 1 \text { a } 2 \text { salários mínimos }\end{array}$ & $\begin{array}{c}\text { IPDA } \\
\text { IURD } \\
\text { CATOLICA } \\
\text { Total }\end{array}$ & $\begin{array}{c}108 \\
68 \\
150 \\
326\end{array}$ & $\begin{array}{l}26,98 \\
29,31 \\
25,39 \\
26,73\end{array}$ & $\begin{array}{c}8,03 \\
8,07 \\
10,63 \\
9,42\end{array}$ & $\begin{array}{l}0,77 \\
0,98 \\
0,87 \\
0,52\end{array}$ & $\begin{array}{c}730,00 \\
28.087,72 \\
28.817,72\end{array}$ & $\begin{array}{c}2 \\
323 \\
325\end{array}$ & 4,197 & 0,016 \\
\hline $\begin{array}{l}\text { Domicílios particulares com rendimento } \\
\text { nominal mensal domiciliar per capita de } \\
\text { mais de } 2 \text { a } 3 \text { salários mínimos }\end{array}$ & $\begin{array}{c}\text { IPDA } \\
\text { IURD } \\
\text { CATOLICA } \\
\text { Total }\end{array}$ & $\begin{array}{c}108 \\
68 \\
150 \\
326\end{array}$ & $\begin{array}{c}6,93 \\
10,49 \\
11,83 \\
9,93\end{array}$ & $\begin{array}{l}4,87 \\
4,56 \\
6,03 \\
5,79\end{array}$ & $\begin{array}{l}0,47 \\
0,55 \\
0,49 \\
0,32\end{array}$ & $\begin{array}{c}1.539,56 \\
9.356,46 \\
10.896,02\end{array}$ & $\begin{array}{c}2 \\
323 \\
325\end{array}$ & 26,574 & 0,000 \\
\hline
\end{tabular}

Fonte: Agregado por setores censitários. Censo Demográfico 2010.

Os dados corroboram com as proposições feitas por Rosas (2012), que afirma que os templos da IPDA e IURD congregam uma população que está inserida em níveis inferiores e intermediários da distribuição de renda, respectivamente. Os templos da IPDA apresentam forte correlação com áreas desprovidas de rendimentos. Áreas onde os templos da IURD estão instalados apresentam rendimentos nominais abaixo e 
Territórios religiosos...

superiores a dois salários mínimos, justificado em grande parte, pelo fato destes templos se fazerem presentes em diferentes estratos da sociedade.

Tabela 7: Características do Domicílio/ Infraestrutura - 2010

\begin{tabular}{|c|c|c|c|c|c|c|c|c|c|}
\hline Variáveis & Templos & № & Média & Desv.Padrão & Erro Padrão & $\begin{array}{l}\text { Soma dos } \\
\text { Quadrados }\end{array}$ & GL & $\mathbf{F}$ & SIG. \\
\hline \multirow{4}{*}{$\begin{array}{l}\text { Domicílios particulares permanentes com energia } \\
\text { elétrica }\end{array}$} & IPDA & 108 & 99,93 & 0,24 & 0,02 & 0,21 & 2 & 4,282 & 0,015 \\
\hline & IURD & 68 & 99,98 & 0,13 & 0,02 & 7,91 & 323 & & \\
\hline & CATOLICA & 150 & 99,99 & 0,07 & 0,01 & 8,12 & 325 & & \\
\hline & Total & 326 & 99,97 & 0,16 & 0,01 & & & & \\
\hline \multirow{4}{*}{$\begin{array}{l}\text { Domicílios particulares permanentes com lixo } \\
\text { coletado, banheiro de uso exclusivo dos } \\
\text { moradores ou sanitário e esgotamento sanitário } \\
\text { via rede geral de } \\
\text { esgoto ou pluvial }\end{array}$} & IPDA & 108 & 90,99 & 19,31 & 1,86 & & & & \\
\hline & IURD & 68 & 97,71 & 5,19 & 0,63 & $3.549,96$ & 2 & 11 & 0,000 \\
\hline & CATOLICA & 150 & 98,13 & 7,74 & 0,63 & $50.646,93$ & 323 & & \\
\hline & Total & 326 & 95,68 & 12,91 & 0,72 & $54.196,89$ & 325 & & \\
\hline \multirow{4}{*}{$\begin{array}{l}\text { Domicílio particular permanente próprio com } \\
\text { iluminação pública }\end{array}$} & IPDA & 108 & 86,61 & 32,40 & 3,12 & & & & \\
\hline & IURD & 68 & 99,91 & 0,68 & 0,08 & $10.927,25$ & 2 & 13 & 0,000 \\
\hline & CATOLICA & 150 & 98,37 & 11,57 & 0,95 & $132.331,28$ & 323 & & \\
\hline & Total & 326 & 94,80 & 21,00 & 1,16 & $143.258,53$ & 325 & & \\
\hline \multirow{4}{*}{$\begin{array}{l}\text { Domicílio particular permanente próprio com } \\
\text { pavimentação }\end{array}$} & IPDA & 108 & 85,17 & 33,18 & 3,19 & & & & \\
\hline & IURD & 68 & 99,16 & 3,88 & 0,47 & $12.909,06$ & 2 & 15 & 0,000 \\
\hline & CATOLICA & 150 & 98,23 & 11,60 & 0,95 & $138.887,05$ & 323 & & \\
\hline & Total & 326 & 94,10 & 21,61 & 1,20 & $151.796,11$ & 325 & & \\
\hline \multirow{4}{*}{$\begin{array}{l}\text { Domicílio particular permanente próprio com } \\
\text { calçada }\end{array}$} & IPDA & 108 & 79,18 & 33,84 & 3,26 & & & & \\
\hline & IURD & 68 & 97,82 & 6,64 & 0,81 & $22.217,79$ & 2 & 23 & 0,000 \\
\hline & CATOLICA & 150 & 96,14 & 14,17 & 1,16 & $155.434,19$ & 323 & & \\
\hline & Total & 326 & 90,87 & 23,38 & 1,29 & $177.651,98$ & 325 & & \\
\hline \multirow{4}{*}{$\begin{array}{l}\text { Domicílio particular permanente próprio com } \\
\text { meio fio }\end{array}$} & IPDA & 108 & 81,81 & 33,56 & 3,23 & & & & \\
\hline & IURD & 68 & 97,82 & 7,32 & 0,89 & $17.015,76$ & 2 & 18 & 0,000 \\
\hline & CATOLICA & 150 & 96,83 & 13,60 & 1,11 & $151.658,41$ & 323 & & \\
\hline & Total & 326 & 92,06 & 22,78 & 1,26 & $168.674,16$ & 325 & & \\
\hline
\end{tabular}

Fonte: Agregado por setores censitários. Censo Demográfico 2010.

Sobre a precariedade da infraestrutura, os dados demonstraram forte relação entre áreas desprovidas de pavimentação, calçada, iluminação pública e esgotamento sanitário com áreas onde tem presença os templos da IPDA. O oposto foi observado nos locais onde os templos católicos se encontram. Estas áreas mostram forte presença de domicílios com coleta de lixo, esgotamento por rede e acessibilidade (Tabela 7). Ao passo que os templos da IURD, apesar de estarem inseridos em contextos sociais distintos, apresentaram relações bem próximas aos templos católicos.

\section{CONSIDERAÇÕES FINAIS}

A análise dos templos, sobretudo sua localização espacial representa um importante instrumento na compreensão do processo de territorialização do espaço levado a cabo por denominações religiosas diversas. As evidências empíricas dão conta de que o espaço de Belo Horizonte encontra-se fragmentado em um mosaico de territórios religiosos, marcados por profundas assimetrias sociais, denotando estratégias locacionais e a busca por públicos diferenciados.

Estudos Geográficos, Rio Claro, 16(1): 41-59, jan./jun. 2018 (ISSN 1678-698X) 
Territórios religiosos...

Os resultados estatísticos demonstraram uma polarização nas condições de vida das populações do entorno imediato dos templos católicos, IPDA e IURD, sobretudo em relação à cor e raça e rendimentos. Percebe-se claramente uma concentração de templos católicos nas áreas mais centrais e nobres da cidade, em contextos sociais marcados pela predominância de população branca, com rendimentos mais altos.

Por outro lado, a análise espacial indicou que os templos IURD e IPDA encontram-se concentrados em áreas periféricas e/ ou aglomerados urbanos, locais onde também se congregam mais fortemente negros e pardos, com rendimentos intermediários e inferiores. A IURD e IPDA souberam aproveitar as omissões ou a ausência do poder público, da presença católica, e da infraestrutura urbana adequada, para atender a uma população carente material e existencialmente, na busca por respostas para as suas inquietações. Esta estratégia também conta com uma liturgia específica, pautada numa comunicação mais direta e aplicada à vida dos fiéis, com cultos dinâmicos e de forte apelo sensorial, no qual testemunhos de fé, palavras de incentivo e esperança reforçam o seu poder de persuasão, convertendo novos fieis e fidelizando os já convertidos, aumentando assim, o seu poder de influência.

A IPDA e a IURD estão organizadas hierarquicamente em organismos supralocais, templo-sede ou igreja-mãe, igrejas filiais, salões e pontos de pregação, o que facilita a sua distribuição pelo território, e as torna mais dinâmicas e independentes uma das outras. Com isso, os templos da IPDA e IURD vêm alimentando o ciclo de reprodução neoprotestante, desempenhando importante papel na conquista de novos territórios, dada a facilidade com que os seus cultos são realizados em pequenos espaços ou salões alugados. Estes locais improvisados vão aos poucos se transformando em templos filiais, concretizando a estratégia de crescimento das igrejas, pautada na descentralização e na informalidade.

Nota-se, portanto, que a territorialidade dos templos, principalmente da IPDA é informal e transitória, sendo definidos em um pequeno espaço de tempo e na mobilidade dos seus espaços sagrados. Em um mesmo bairro podem ser encontrados dois ou mais templos de uma mesma denominação religiosa competindo entre si. Com isso, novos territórios de atuação religiosa são delimitados a cada momento, podendo até mesmo haver superposições territoriais para uma mesma denominação. Além disso, ao contrário dos templos católicos, estas denominações evangélicas apresentam um processo de coesão, que as leva a localizarem-se próximas uma das outras.

Situação diversa é vivida pela igreja Católica. Apesar de a maioria de seus templos encontrarem-se concentrados nas áreas mais nobres da cidade, as cerimônias religiosas guardam relações tênues com a dinâmica e complexa realidade dos seus fieis, fato que tem se traduzido em frequência reduzida e reconversões a outras religiões. Some-se a isso o fato de que a abertura de um novo templo católico não pode prescindir de uma edificação própria e apropriada e de um longo processo comandado pela estrutura organizacional centralizada e burocrática da Igreja.

O nosso esforço de análise sobre as dinâmicas espaciais permite afirmar a existência de uma lógica espacial diferenciada em relação aos territórios religiosos no espaço urbano de Belo Horizonte, entre as denominações estudadas que reforçam a necessidade de se estudar na escala intraurbana a construção dos territórios religiosos, elemento fundamental à compreensão das mudanças estruturais em curso na adesão religiosa dos brasileiros.

Estudos Geográficos, Rio Claro, 16(1): 41-59, jan./jun. 2018 (ISSN 1678-698X)

http://www.periodicos.rc.biblioteca.unesp.br/index.php/estgeo 


\section{REFERÊNCIAS BIBLIOGRÁFICAS}

ANTONIAZZI, A. Catolicismo em Belo Horizonte na proximidade do novo milênio. In: Cadernos de História. Belo Horizonte: PUC Minas. v. 2, n. 3, 1997, p. 69-85.

ARQUIDIOCESE DE BELO HORIZONTE. Catálogo de Paróquias. Belo Horizonte. Disponível em:<http://www.arquidiocesebh.org.br/catalogo/paroquias.php? paroquiaAtual=cidade>. Acesso em: 19 mar. 2016.

BLALOCK, H.M.Social Statistics.McGraw-Hill. 640 p. 1979.

BOURDIEU, P. Gênese e estrutura do campo religioso. In: BOURDIEU, P. (Org.) A economia das trocas simbólicas. São Paulo: Perspectiva, $5^{a}$ ed., 1999, p. 27-98.

BROWN, J. A. C. A natureza da conversão religiosa. In: BROWN, J. A. C. Técnicas de persuasão: da propaganda à lavagem cerebral. Rio de Janeiro: Zahar, 1965, p. 211230.

CAMPOS JR., L. C. Pentecostalismo: sentidos da palavra divina. São Paulo: Ática, 166 p. 1995.

CORRÊA. R. L. Espaço: um conceito-chave da Geografia. In: CASTRO, I. E. de; GOMES, P. C. da C.; CORREAA, R. L. (Org.). Geografia: conceitos e temas. Rio de Janeiro: Bertrand, $3^{\mathrm{a}}$ ed. 2001, p. 15-47.

FARIA. J.R. Minas Gerais registra cinco novas igrejas a cada dois dias. O Tempo. Caderno Cidades. Belo Horizonte, 16 abr. 2017. Disponível em:<http://www.otempo.com.br/cidades/minas-gerais-registra-cinco-novas-igrejas-acada-dois-dias-1.1461305> Acesso em: 18 abr. 2017.

FERNANDES, R. C. Novo nascimento: os evangélicos em casa, na igreja e na política. Rio de Janeiro: Mauad, 1998.

GIL FILHO, S.F. Estruturas da Territorialidade Católica no Brasil. Scripta Nova. Revista Eletrônica de Geografia y Ciências Sociales, Universidad de Barcelona, v. 10, n. 205, 2006.

GUIMARÃES. B. M. As favelas da Região Metropolitana de Belo Horizonte: desafios e perspectivas. Cadernos Metrópole. São Paulo. Puc São Paulo. n. 5, 2001, p. 48-61. 
Territórios religiosos...

IGREJA PENTECOSTAL DEUS É AMOR. Igrejas pelo Brasil. Belo Horizonte. Disponível em: <http://www.ipda.com.br/ipda/ipda/enderecos/minas_gerais.html>. Acesso em: 19 mar. 2016.

IGREJA UNIVERSAL DO REINO DE DEUS. Endereços Universal. Belo Horizonte. Disponível em: <http://www.universal.org/enderecos/busca/belo-horizonte/>. Acesso em: 19 mar. 2016.

INSTITUTO BRASILEIRO DE GEOGRAFIA E ESTATÍSTICA. IBGE. Base de informações do Censo Demográfico 2010: Resultado do Universo por setor censitário. Rio de Janeiro, 2011.

LUCKMANN, T. The invisiblereligion. New York: Macmillan, Bologna: II Mulino, 1969.

RAFFESTIN, C. Por uma Geografia do Poder. São Paulo: Ática, 1993.

RIBEIRO, R. R. Histórias de bairros [de] Belo Horizonte. Belo Horizonte. Arquivo Público da Cidade. Prefeitura de Belo Horizonte. 2011. 62 p.

ROSAS, N. As ações sociais da Igreja Universal: Recrutamento e empreendedorismo no "A Gente da Comunidade de Belo Horizonte". Revista Ciências Sociais e Religião, Porto Alegre, ano 14, n. 17, p. 27-51, jul. 2012.

ROSENDAHL Z. Território e Territorialidade: uma perspectiva geográfica para o estudo da religião. In: ANAIS DO X ENCONTRO DE GEÓGRAFOS DA AMÉRICA LATINA, 20 a 26 de março de 2005. São Paulo. Universidade de São Paulo. p. 1 - 15.

SCHULTZ, A. Deus está presente - o diabo está no meio: o protestantismo e as estruturas teológicas do imaginário religioso brasileiro. 2005. (Tese de Doutorado em Teologia). São Leopoldo: Escola Superior de Teologia - EST. 405 p.

WERNECK, G.; KIEFER, S. De maioria católica, BH tem espaço para diversidade religiosa. Portal Uai. Belo Horizonte, 06 abr. 2015. Disponível em:<http://www.em.com.br/app/noticia/gerais/2015/04/06/interna_gerais,634625/capitalde-todas-as-crencas.shtml>Acesso em: 12 jul. 2016. 